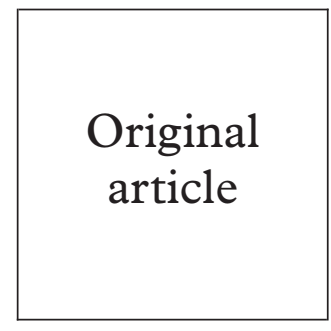

\title{
Prevalence of HIV-1 among attenders at sexually transmitted disease clinics: analyses according to country of birth
}

\author{
Christine A McGarrigle, Angus Nicoll for a collaborative group $\star$
}

\begin{abstract}
Objectives: To determine the importance of world region of birth as a risk factor for HIV-1 infection, the likelihood of having an HIV-1 infection diagnosed and the likelihood of having another coexisting acute sexually transmitted infection (STI) among attenders at genitourinary medicine clinics.
\end{abstract}

Subjects: Specimens from attenders having routine syphilis serology at 15 sexually transmitted disease clinics in England, Wales, and Northern Ireland participating in the unlinked anonymous seroprevalence monitoring programme from 1994 to 1996.

Methods: Limited data were collected with specimens that were irreversibly unlinked from the source patients before testing for antibodies to HIV-1. Numbers of specimens, the prevalence of HIV-1, the proportions of infections clinically diagnosed, and the presence of coexisting acute STIs were analysed according to world region of birth, sexual orientation, and injecting drug use. Results: Between 1994 and 1996, 173075 specimens were collected; 16.9\% were from people born outside the United Kingdom. Risk of being HIV-1 positive was significantly higher overall for both men and women born abroad, but this was not the case for those born in south Asia (India, Pakistan, and Bangladesh). Homosexual and bisexual males born abroad were almost twice as likely to be HIV infected as their counterparts born in the United Kingdom. However, homosexual and bisexual men born in the United Kingdom accounted for almost three quarters of the $1174 \mathrm{HIV}-1$ positive specimens detected. Among 158728 non-drug injecting heterosexuals the highest prevalence was observed in specimens from those men $(4.0 \%)$ and women $(5.8 \%)$ born in sub-Saharan Africa. The 6991 heterosexual men and women born in other European countries were also more likely to provide HIV-1 positive specimens than UK born heterosexuals. However, $39 \%$ of the HIV-1 positive specimens in heterosexuals come from clinic attenders born in the United Kingdom. Heterosexual males were generally less likely to have their infection diagnosed than females. There were 182 attendances (mostly from London clinics) non-drug injecting heterosexual men and women who were infected with both HIV-1 and an acute sexually transmitted infection; only $12 \%$ of whom had had their HIV-1 infection diagnosed.

Conclusion: Among most people attending genitourinary medicine clinics, being born abroad is associated with an increased likelihood for HIV-1 infection. HIV-1 infected heterosexuals, of whom $46 \%$ are people from sub-Saharan Africa, are unlikely to have their infection clinically diagnosed and thus are unable to obtain appropriate treatment. The presence of HIV-1 infected heterosexual men and women with acute STI represents a potential source of heterosexual HIV transmission both for those born in the United Kingdom and born abroad.

(Sex Transm Inf 1998;74:415-420)

Keywords: HIV; country of birth; STD clinic attenders; unlinked anonymous surveillance

\section{Introduction}

Infection with human immunodeficiency virus type 1 (HIV-1), in common with other sexually transmitted infections (STIs), is distributed heterogeneously in populations in the United Kingdom. ${ }^{1}$ The virus with its associated spectrum of disease has spread rapidly in a number of developing and developed countries since the first recognition of AIDS 15 years ago. ${ }^{2}$ High levels of transmission have already occurred in parts of sub-Saharan Africa, South East Asia, the Americas, and southern Europe, ${ }^{2}$ and recently rapid spread has been recorded in parts of the Indian subcontinent (south Asia) and eastern Europe. ${ }^{2}$ The British population is richly international; around $9 \%$ of the young adult population were born abroad and people living in the United Kingdom make over 12 million trips abroad annually. ${ }^{45}$ Exposure abroad in countries where the prevalence of infection is high is recognised as a risk factor for HIV-1 infection. ${ }^{16}$ Many countries where HIV is now endemic have important historical links with the United Kingdom through its colonial past, Commonwealth countries in sub-Saharan Africa, the Indian subcontinent, and the Caribbean contain around $60 \%$ of prevalent HIV worldwide. ${ }^{2}$ Equally, neighbouring countries in Europe such as France, Italy, and Spain have prevalences of HIV which are threefold to sixfold higher than that of the United Kingdom. ${ }^{2}$ Population movement for holidays, business, or domicile between both types of country and the United Kingdom is commonplace. ${ }^{5}$ Both ethnic origin and country of birth are very relevant in investigating the contribution of infections acquired abroad.

Data gathered from the results of voluntary confidential HIV testing provide important 
Table 1 Survey of genitourinary medicine clinic attenders: HIV-1 prevalence by world region of birth and sex, 1994-6

\begin{tabular}{|c|c|c|c|c|c|c|c|c|c|c|c|}
\hline & $U K$ & $\begin{array}{l}\text { Rest of } \\
\text { Europe }\end{array}$ & $\begin{array}{l}\text { Sub-Saharan } \\
\text { Africa }\end{array}$ & Caribbean & Australasia & $\begin{array}{l}\text { North Africa and } \\
\text { Middle East }\end{array}$ & $\begin{array}{l}\text { Central and } \\
\text { South America }\end{array}$ & $\begin{array}{l}\text { South } \\
\text { Asia }\end{array}$ & $\begin{array}{l}\text { North } \\
\text { America }\end{array}$ & $\begin{array}{l}\text { East and South } \\
\text { East Asia }\end{array}$ & Total $^{\star}$ \\
\hline \multicolumn{12}{|l|}{ Males: } \\
\hline Total & 74930 & 3552 & 3427 & 2294 & 1048 & 1456 & 698 & 951 & 631 & 523 & 89510 \\
\hline HIV-1 Pos & 1050 & 175 & 153 & 21 & 42 & 14 & 52 & 4 & 37 & 21 & 1569 \\
\hline \% Positive & 1.40 & 4.93 & 4.46 & 0.92 & 4.01 & 0.96 & 7.45 & 0.42 & 5.86 & 4.02 & 1.75 \\
\hline \multicolumn{12}{|l|}{ Females: } \\
\hline Total & 68826 & 4541 & 3293 & 1841 & 1517 & 779 & 829 & 543 & 691 & 705 & 83565 \\
\hline HIV-1 Pos & 95 & 36 & 189 & 7 & 3 & 2 & 6 & 0 & 2 & 3 & 343 \\
\hline \% Positive & 0.14 & 0.79 & 5.74 & 0.38 & 0.20 & 0.26 & 0.72 & 0.00 & 0.29 & 0.43 & 0.41 \\
\hline \multicolumn{12}{|l|}{ All (total) ${ }^{\star}$} \\
\hline Total & 143756 & 8093 & 6720 & 4135 & 2565 & 2235 & 1527 & 1494 & 1322 & 1228 & 173075 \\
\hline HIV-1 Pos & 1145 & 211 & 342 & 28 & 45 & 16 & 58 & 4 & 39 & 24 & 1912 \\
\hline$\%$ Positive & 0.80 & 2.61 & 5.09 & 0.68 & 1.75 & 0.72 & 3.80 & 0.27 & 2.95 & 1.95 & 1.10 \\
\hline
\end{tabular}

^ Excludes 934 specimens where sex was not recorded and 26799 where country of birth was not recorded.

insights into the burden of infection experienced in the United Kingdom in individuals who acquired their infection elsewhere, including those born abroad. ${ }^{7}$ However, this source of information can only apply to those seeking or being offered HIV testing. ${ }^{6}$ Evidence shows that people originating in developing countries may be especially unlikely to seek, or be offered, diagnostic HIV testing ${ }^{8}$ and that therefore the unlinked anonymous approach based on specimens gathered routinely will be particularly useful in contributing to the surveillance of these groups. ${ }^{6}$

\section{Methods}

An unlinked anonymous HIV survey involving patients attending genitourinary medicine (GUM) clinics was initiated in England, Wales, and Northern Ireland from 1990. ${ }^{6}$ The survey expanded to include 15 clinics in 1994 . In each clinic it is routine practice to perform diagnostic syphilis serology on all patients attending for a new episode relating to a new risk of sexually transmitted infection (STI). Individuals presenting for the first time within a calendar quarter are eligible for the survey and the residue of their syphilis specimen, after completion of diagnostic testing, is collected for HIV testing. A limited set of epidemiological and clinical data were retained with the specimen including sexual orientation, sex, drug injecting behaviour, whether the subject had had HIV infection diagnosed, and whether they had an acute STI at the time of consultation. ${ }^{9}$ Concurrent acute STI was recorded if one or more of the following diagnoses were made at the time of specimen collection. The category "acute STI" included infectious syphilis, postpubertal gonorrhoea (uncomplicated and complicated), chancroid, donovanosis, lymphogranuloma venereum, chlamydia (uncomplicated and complicated), non-specific urethritis (NSU), trichomoniasis, scabies/ pediculosis, herpes simplex (first attack), wart virus infection (first attack), and molluscum contagiosum. Since 1993, following a recommendation of a Medical Research Council overview committee, country of birth (when available) has been included in the data retained. ${ }^{6}$

Data reviewed here were for the 3 year period 1994-6. Clinics introduced the collection of country of birth at different times over the study period, so that there were a substantial number of specimens in 1994 for which country of birth information was unavailable (Table 1). ${ }^{6}$

After irreversible unlinking from patient identifiers, residual sera were tested using conventional enzyme immunoassays (EIAs) for HIV. All initially reactive specimens were tested and infections confirmed in the Virus Reference Division of the Central Public Health Laboratory, Colindale, using the currently standard test algorithm. ${ }^{6}$

Before analysis, data from individual clinics were combined and information on specific countries of birth was reduced to 10 world geographic regions (Table 1). Prevalence of anti-HIV-1 (referred to as HIV-1) was determined among all patients, and then stratified by sex and sexual orientation; (homosexual and bisexual males, heterosexual males and females, excluding those known to have injected drugs) and according to world region of birth. Comparisons of HIV-1 prevalence were made for the 10 regions of birth according to sex and exposure category. Comparisons were also made for the proportions of HIV-1 positive specimens from people whose HIV-1 infection was known to have been clinically diagnosed and the proportions of those from an individual with an acute STI. All comparisons were made using $\chi^{2}$ tests in STATA version 5.0.

\section{Results}

Between January 1994 and December 1996 results were received for 173075 specimens where country of birth was recorded. Specimens from people born outside the United Kingdom accounted for 29319 (16.9\%) of this total. The three largest regional categories were the "Rest of Europe" 8093 specimens (4.7\%), "Sub-Saharan Africa", 6720 (3.9\%), and the "Caribbean" 4135 (2.4\%) (Table 1).

Of the 173075 specimens, 1912 (1.1\%) were HIV-1 antibody positive. Although individuals born in the United Kingdom accounted for $59.9 \%$ (1145 of 1912) of HIV-1 positive specimens, the proportion positive in this group (1145 of $143756,0.8 \%$ ) was low. HIV-1 positivity was significantly higher in specimens from men and women born abroad overall (odds ratio $3.3 ; 95 \%$ confidence interval 3.0-3.6). The risk of being HIV-1 positive was higher for those born in the rest of Europe, North America, Central and South America, sub-Saharan Africa, East and South East Asia, and Australasia (Table 1). Prevalence was lowest in those born in South Asia. Males were 
Table 2 Survey of genitourinary medicine clinic attenders: HIV-1 prevalence by world region of birth and risk group, 1994-6

\begin{tabular}{|c|c|c|c|c|c|c|c|c|c|c|c|}
\hline $\begin{array}{l}\text { Exposure } \\
\text { category }\end{array}$ & $U K$ & $\begin{array}{l}\text { Rest of } \\
\text { Europe }\end{array}$ & $\begin{array}{l}\text { Sub-Saharan } \\
\text { Africa }\end{array}$ & Caribbean & Australasia & $\begin{array}{l}\text { North Africa and } \\
\text { Middle East }\end{array}$ & $\begin{array}{l}\text { Central and } \\
\text { South America }\end{array}$ & $\begin{array}{l}\text { South } \\
\text { Asia }\end{array}$ & $\begin{array}{l}\text { North } \\
\text { America }\end{array}$ & $\begin{array}{l}\text { East and South } \\
\text { East Asia }\end{array}$ & Total \\
\hline \multicolumn{12}{|c|}{ Homo/bisexual males: } \\
\hline Total & 9706 & 902 & 215 & 49 & 260 & 79 & 232 & 59 & 214 & 106 & 11822 \\
\hline HIV-1 Pos & 855 & 134 & 27 & 7 & 38 & 12 & 46 & 2 & 34 & 19 & 1174 \\
\hline$\%$ Positive & 8.81 & 14.86 & 12.56 & 14.29 & 14.62 & 15.19 & 19.83 & 3.39 & 15.89 & 17.92 & 9.93 \\
\hline \multicolumn{12}{|c|}{ Male heterosexuals ${ }^{\star}:$} \\
\hline Total & 63970 & 2550 & 3181 & 2224 & 761 & 1363 & 460 & 883 & 404 & 412 & 76208 \\
\hline HIV-1 Pos & 181 & 26 & 126 & 14 & 4 & 2 & 6 & 2 & 1 & 2 & 364 \\
\hline \multicolumn{12}{|c|}{ Female heterosexuals ${ }^{\star}$ : } \\
\hline Total & 67983 & 4441 & 3270 & 1841 & 1480 & 773 & 820 & 542 & 671 & 699 & 82520 \\
\hline HIV-1 Pos & 86 & 23 & 189 & 7 & 2 & 2 & 6 & 0 & 0 & 3 & 318 \\
\hline$\%$ Positive & 0.13 & 0.52 & 5.78 & 0.38 & 0.14 & 0.26 & 0.73 & 0.00 & 0.00 & 0.43 & 0.39 \\
\hline \multicolumn{12}{|c|}{ Other categories: } \\
\hline Total & 2097 & 200 & 54 & 21 & 64 & 20 & 15 & 10 & 33 & 11 & 2525 \\
\hline HIV-1 Pos & 23 & 28 & 0 & 0 & 1 & 0 & 0 & 0 & 4 & 0 & 56 \\
\hline \% Positive & 1.10 & 14.00 & 0.00 & 0.00 & 1.56 & 0.00 & 0.00 & 0.00 & 12.12 & 0.00 & 2.22 \\
\hline \multicolumn{12}{|c|}{ All exposure categoriest: } \\
\hline Total & 143756 & 8093 & 6720 & 4135 & 2565 & 2235 & 1527 & 1494 & 1322 & 1228 & 173075 \\
\hline
\end{tabular}

$\star$ Excludes those where drug injecting was recorded.

† Excludes 934 specimens where sex was not recorded and 26799 where country of birth was not recorded.

more likely to be infected than females overall (odds ratio 4.3; 95\% confidence interval 3.9-4.9) (Table 1). Except for south Asia and sub-Saharan Africa specimens, those from males were significantly more likely to be HIV-1 positive than those from females for every geographic region (Table 1). For those in the "South Asia" category there was no evidence of a difference in HIV-1 prevalence between men and women and in the "SubSaharan Africa" category men were significantly less likely to be HIV-1 infected then women (odds ratio $0.77 ; 95 \%$ confidence interval 0.62-0.95). After stratification by sexual orientation (Table 2), much, but not all of the excess of infection in males was explained by the importance of sex between men as a risk factor for HIV-1 infection in males.

HIV RISK GROUPS

Homosexual and bisexual men

In this risk group overall HIV-1 prevalence was $15.1 \%$ (319 of 2116) among homosexual and bisexual men born abroad and was $8.8 \%(855$ of 9706) in men born in the United Kingdom (Table 2). HIV-1 prevalence was higher for those in all world regions of birth apart from

Table 3 Survey of genitourinary medicine clinic attenders: comparison of HIV-1 prevalence between UK born clinic attenders and attenders from other world regions of birth

\begin{tabular}{llll}
\hline Exposure category & World region of birth & Odds ratio & (95\% Confidence interval) \\
\hline Homosexual and bisexual men & UK & 1 & \\
& Rest of Europe & 1.81 & $(1.48-2.20)$ \\
& Caribbean & 1.73 & $(0.79-3.78)$ \\
Sub-Saharan Africa & 1.49 & $(0.99-2.23)$ \\
& South Asia & 0.36 & $(0-1.35)$ \\
& Born abroad & 1.84 & $(1.60-2.11)$ \\
& UK & 1 & \\
Heterosexual men & Rest of Europe & 3.63 & $(2.41-5.47)$ \\
& Caribbean & 2.23 & $(1.30-3.83)$ \\
& Sub-Saharan Africa & 14.54 & $(11.55-18.29)$ \\
& South Asia & 0.8 & $(0-2.94)$ \\
& Born abroad & 5.35 & $(4.35-6.57)$ \\
Heterosexual women & UK & 1 & \\
& Rest of Europe & 4.11 & $(2.60-6.49)$ \\
& Caribbean & 3.01 & $(1.42-6.40)$ \\
& Sub-Saharan Africa & 48.43 & $(37.46-62.61)$ \\
& South Asia & 0 & - \\
& Born abroad & 12.8 & $(10.00-16.40)$ \\
\hline
\end{tabular}

south Asia than it was in men born in the United Kingdom (Table 3). Homosexual or bisexual men born in the United Kingdom contributed $72.8 \%$ (855 of 1174 ) of HIV-1 positive specimens in this exposure category and $44.7 \%$ (855 of 1912 ) of all HIV-1 positive specimens detected (Table 2).

\section{Heterosexual men and women}

Among heterosexual men and women where drug injecting was not recorded as a risk factor, those born in the United Kingdom, contributed $83.1 \%$ (131953 of 158728 ) of the total specimens included but only contributed $39.1 \%$ (267 of 682 ) of HIV-1 positive specimens (Table 2). HIV-1 prevalence was highest among heterosexual men $(4.0 \%)$ and women $(5.8 \%)$ born in sub-Saharan Africa. These prevalences were 14 times higher than those in men $(0.3 \%)$ and 48 times higher in women $(0.1 \%)$ born in the United Kingdom (Table 3$)$. Heterosexual men and women born in the rest of Europe also had a significantly higher HIV-1 prevalence than those born in the United Kingdom (Table 3), as did those born in the Caribbean (Table 3). Prevalence was very low among the relatively small number of noninjecting heterosexual men and women from south Asia. The region of birth sub-Saharan Africa accounted for $46.2 \%$ (315 of 682 ) of HIV-1 positive specimens detected from heterosexuals.

\section{Injecting drug users}

There were 1572 specimens from individuals for whom drug injecting had been recorded. Of these $44(2.8 \%)$ were HIV-1 positive (data not shown). Seventeen of the 44 were from injecting drug users (IDU) born in the United Kingdom (HIV-1 prevalence of $1.3 \%$ ). Twenty four of the 147 specimens $(16.3 \%)$ from individuals born in the rest of Europe were HIV-1 positive.

DIAGNOSED AND UNDIAGNOSED HIV INFECTIONS Overall, $60.1 \%$ (763 of 1912) of HIV-1 positive specimens were from people whose infections had been diagnosed. This proportion differed by global region of birth (Table 4). Overall, 
Table 4 Survey of genitourinary medicine clinic attenders 1994-6: diagnosed and undiagnosed HIV infections by region of birth and exposure category

\begin{tabular}{|c|c|c|c|c|c|c|c|c|c|c|c|}
\hline Exposure category & $U K$ & $\begin{array}{l}\text { Rest of } \\
\text { Europe }\end{array}$ & $\begin{array}{l}\text { Sub-Saharan } \\
\text { Africa }\end{array}$ & Caribbean & Australasia & $\begin{array}{l}\text { North Africa and } \\
\text { Middle East }\end{array}$ & $\begin{array}{l}\text { Central and } \\
\text { South America }\end{array}$ & $\begin{array}{l}\text { South } \\
\text { Asia }\end{array}$ & $\begin{array}{l}\text { North } \\
\text { America }\end{array}$ & $\begin{array}{l}\text { East and South } \\
\text { East Asia }\end{array}$ & Total \\
\hline \multicolumn{12}{|c|}{ Homo/bisexual males: } \\
\hline No diagnosed & 593 & 101 & 17 & 3 & 29 & 9 & 32 & 1 & 22 & 11 & 818 \\
\hline \% Diagnosed & 69.36 & 75.37 & 62.96 & 42.86 & 76.32 & 75.00 & 69.57 & 50.00 & 64.71 & 57.89 & 69.68 \\
\hline \multicolumn{12}{|c|}{ Male heterosexuals ${ }^{\star}$ : } \\
\hline No diagnosed & 67 & 10 & 49 & 3 & 2 & 2 & 2 & 1 & 0 & 1 & 137 \\
\hline Total HIV pos & 181 & 26 & 126 & 14 & 4 & 2 & 6 & 2 & 1 & 2 & 364 \\
\hline \% Diagnosed & 37.02 & 38.46 & 38.89 & 21.43 & 50.00 & 100.00 & 33.33 & 50.00 & 0.00 & 50.00 & 37.64 \\
\hline \multicolumn{12}{|c|}{ Female heterosexuals ${ }^{\star}:$} \\
\hline No diagnosed & 40 & 15 & 87 & 3 & 1 & 1 & 2 & 0 & 0 & 2 & 151 \\
\hline Total HIV pos & 86 & 23 & 189 & 7 & 2 & 2 & 6 & 0 & 0 & 3 & 318 \\
\hline \% Diagnosed & 46.51 & 65.22 & 46.03 & 42.86 & 50.00 & 50.00 & 33.33 & - & - & 66.67 & 47.48 \\
\hline \multicolumn{12}{|l|}{ Other categoriest: } \\
\hline No diagnosed & 16 & 23 & 0 & 0 & 1 & 0 & 0 & 0 & 3 & 0 & 43 \\
\hline Total HIV pos & 23 & 28 & 0 & 0 & 1 & 0 & 0 & 0 & 4 & 0 & 56 \\
\hline \% Diagnosed & 69.57 & 82.14 & - & - & 100.00 & - & - & - & 75.00 & - & 76.79 \\
\hline \multicolumn{12}{|c|}{ All exposure categories: } \\
\hline No diagnosed & 716 & 149 & 153 & 9 & 33 & 12 & 36 & 2 & 25 & 14 & 1149 \\
\hline
\end{tabular}

* Excludes those where drug injecting was recorded.

† Includes injecting drug users and specimens where sexual orientation was not recorded.

males were more likely to have had their infection diagnosed than females (odds ratio 1.6; $95 \%$ confidence interval $1.2-2.0$ ) but this was mostly accounted for by the higher diagnosis rate in those recorded as homosexual and bisexual (Table 4). In total, 30.6\% (356 of 1174 ) of HIV-1 positive specimens from homosexual or bisexual men were from patients whose infection had not been diagnosed (Table 4). There was no difference in the proportion diagnosed for homosexual and bisexual men born abroad compared with those born in the United Kingdom $(p=0.7216)$. Thirty seven per cent (67 of 181) of infections among non-injecting male heterosexuals born in the United Kingdom had been diagnosed and $46.5 \%$ (40 of 86 ) of females (Table 4 ). The

Table 5 Survey of genitourinary medicine clinic attenders by exposure category, sexually transmitted infection status, percentage diagnosed, and world region of birth, 1994-6

\begin{tabular}{|c|c|c|c|c|c|}
\hline \multirow[b]{2}{*}{ Exposure category } & \multirow[b]{2}{*}{$\begin{array}{l}\text { Sexually transmitted } \\
\text { infection status }\end{array}$} & \multicolumn{3}{|c|}{ World region of birth } & \multirow[b]{2}{*}{ Total } \\
\hline & & $U K$ & $\begin{array}{l}\text { Sub-Saharan } \\
\text { Africa }\end{array}$ & Rest† & \\
\hline \multirow[t]{10}{*}{ Homosexual and bisexual males } & Acute STI & & & & \\
\hline & Total tested & 2615 & 55 & 493 & 3163 \\
\hline & HIV-1 positive & 216 & 2 & 66 & 284 \\
\hline & $\%$ diagnosed & 42 & 0 & 48 & 43 \\
\hline & Prevalence (\%) & 8.26 & 3.64 & 13.39 & 8.98 \\
\hline & Non-acute & & & & \\
\hline & Total tested & 7091 & 160 & 1408 & 8659 \\
\hline & HIV-1 positive & 639 & 25 & 226 & 890 \\
\hline & $\%$ diagnosed & 79 & 68 & 78 & 78 \\
\hline & Prevalence (\%) & 9.01 & 15.63 & 16.05 & 1.10 \\
\hline \multirow[t]{10}{*}{ Male heterosexuals* } & Acute STI & & & & \\
\hline & Total tested & 25765 & 1313 & 3328 & 30406 \\
\hline & HIV-1 positive & 60 & 35 & 19 & 114 \\
\hline & $\%$ diagnosed & 12 & 9 & 16 & 11 \\
\hline & Prevalence (\%) & 0.23 & 2.67 & 0.57 & 0.37 \\
\hline & Non-acute & & & & \\
\hline & Total tested & 38205 & 1868 & 5729 & 45802 \\
\hline & HIV-1 positive & 121 & 91 & 38 & 250 \\
\hline & $\%$ diagnosed & 50 & 51 & 47 & 50 \\
\hline & Prevalence (\%) & 0.32 & 4.87 & 0.66 & 1.10 \\
\hline \multirow[t]{10}{*}{ Female heterosexuals* } & Acute STI & & & & \\
\hline & Total tested & 18698 & 672 & 2076 & 21446 \\
\hline & HIV-1 positive & 20 & 39 & 9 & 68 \\
\hline & $\%$ diagnosed & 20 & 8 & 22 & 13 \\
\hline & Prevalence (\%) & 0.11 & 80 & 0.43 & 0.32 \\
\hline & Non-acute & & & & \\
\hline & Total tested & 49285 & 2598 & 9191 & 61074 \\
\hline & HIV-1 positive & 66 & 150 & 34 & 250 \\
\hline & $\%$ diagnosed & 55 & 56 & 65 & 57 \\
\hline & Prevalence (\%) & 0.13 & 77 & 0.37 & 0.41 \\
\hline
\end{tabular}

^ Excludes those known to inject drugs.

† Excludes 26131 specimens with country of birth not recorded. proportion of HIV infections diagnosed were similar for non-injecting heterosexual men and women born in the rest of Europe, the Caribbean, and sub-Saharan Africa (Table 4). Of the 44 HIV-1 positive specimens among people reporting drug use, six were from people whose infection remained undiagnosed. Five out of the six of these specimens were from male injectors.

ACUTE SEXUALLY TRANSMITTED INFECTIONS AT TIME OF SPECIMEN COLLECTION

There were 55015 specimens from people presenting with an acute STI, of which 3163 were from homosexual or bisexual males and 51852 from non-injecting heterosexuals. Two hundred and eighty four of the $3163(9.0 \%)$ specimens from homosexual and bisexual males were HIV-1 infected (Table 5). Forty three per cent (122) of the $284 \mathrm{HIV}-1$ positive men with an acute STI had their HIV-1 infection clinically diagnosed while $162(57.0 \%)$ seemingly remained undiagnosed at the end of the consultation (Table 5). When considered by region of birth, HIV-1 prevalence among homosexual and bisexual males with an acute STI who were born in the rest of Europe was $12.9 \%$; (30 of 232), higher than for males born in the United Kingdom $(8.3 \% ; 216$ of 2615) (odds ratio $1.5 ; 95 \%$ confidence interval 1.1-2.3). There was, however, no difference in the likelihood of their HIV infection having being diagnosed. One hundred and eighty two of the $55015(0.3 \%)$ specimens with acute STI from heterosexuals were also infected with HIV-1 (Table 5). Eighty four per cent (153 of 182 ) of these cases were among people attending London clinics. Eighty cases of combined HIV-1 and acute STI infections were found among the 131953 specimens from heterosexual men and women born in the United Kingdom and 74 among the 6451 specimens from men and women born in sub-Saharan Africa (Table 5). Only 22 of $182(12.1 \%)$ of the HIV-1 infections in men and women with acute STIs were diagnosed (Table 5). The proportions were similar for those born in the United 
Kingdom, $13.8 \%$ (11 of 80 ) and men and women born in sub-Saharan Africa $8.1 \%$ (six of 74).

\section{Discussion}

Although the majority of GUM clinic attenders whose specimens contributed to this survey were born in the United Kingdom, a considerable number were collected from people who were born abroad. The proportions of attenders born abroad $(17 \%)$ is higher than the proportion of young adult population recorded as born outside the United Kingdom in the 1991 census $(7 \%) .{ }^{4}$ This is not unexpected as a number of the source countries carry a higher burden of STIs than the United Kingdom. ${ }^{2}$ The findings demonstrate that country of birth is strongly associated with HIV-1 infection in GUM clinic attenders. This has been noticed in at least two other countries. ${ }^{10}{ }^{11}$ Homosexual and bisexual males born abroad have higher HIV infection rates than those born in the United Kingdom. Among heterosexual men and women, in addition to the well known association with time spent in sub-Saharan Africa, ${ }^{12}$ being born in other parts of Europe, Central and South America, and the Caribbean was associated with increased likelihood of HIV infection. It is disquieting that the proportions of infections that are diagnosed among heterosexuals were so low (Table 4). This suggests that diagnostic as well as health promotion services need to be targeted towards heterosexuals. All these findings will further inform HIV testing strategies in GUM clinics though care must be taken not to stigmatise or blame those born abroad. Country of birth must not be confused with ethnic group ${ }^{13}$ and there will have been specimens in the survey from individuals of black and Asian ethnicity who were born in the United Kingdom and therefore included in this category, just as there probably have been people of south Asian ethnicity born in sub-Saharan Africa. As ethnicity was not recorded, this survey cannot give information about levels of HIV infection among black Africans and black Caribbeans born in the United Kingdom who attended GUM clinics. These are groups whose members may be at increased risk of acquiring HIV infection through sex between men and women. ${ }^{14}$ Gathering ethnic group data within the unlinked surveys would clearly be desirable if comparability and consistency in ethnic group coding between clinics could be assumed. ${ }^{13} 15$ The difference in HIV prevalence between heterosexuals born in sub-Saharan Africa and the United Kingdom supports other information emphasising the importance of the epidemic in sub-Saharan Africa to the $\mathrm{UK}^{5}{ }^{11}$ No evidence was found here that transmissions occurring in south Asia have yet had similar impact. However, while the unlinked anonymous methodology minimises participation bias within its setting, ${ }^{6}$ it is possible that people born in south Asia are less likely than people born in other world regions to seek treatment at STI clinics. The number of specimens in this survey from people born in south Asia is disproportionately low compared with the number of people born in south Asia recorded as living in the United Kingdom in the 1991 census. ${ }^{4}$ This may, of course, simply reflect a low burden of STIs, including HIV, within this group. However, the global epidemics of HIV are also changing, with continuing intensification in India, southern Africa, Eastern Europe, and perhaps other regions. ${ }^{2}$ This indicates a need for continuing surveillance and for finer definitions-for example, looking at different regions of sub-Saharan Africa (east, west, and southern Africa) as the United Kingdom pattern of HIV among people born abroad is very likely to change.

It has been demonstrated that the presence of acute STIs, particularly ones producing ulcerative conditions, will facilitate heterosexual transmission of HIV. ${ }^{16}$ Hence, the data on co-infection with HIV and an acute STI infection indicates substantial biological and behavioural potential for in-country HIV transmission. This was true both for people born abroad and in the United Kingdom. It is of concern that $88 \%$ of these HIV infections $(89 \%$ in male and $87 \%$ in female heterosexuals) remained undiagnosed indicating both a failure of diagnostic testing services and the likelihood of ongoing risk of HIV transmission. This survey would not have been possible without the support of hospitals, whose help is gratefully acknowledged. The survey hospitals, whose help is gratefully acknowledged. The survey and programme from which these data are extracted relied heavily on the contribution of Ms Julie Newham, Dr John Parry, and Dr Philip Mortimer of the Virus Reference Division, PHLS,
for their management of all laboratory aspects of the survey, for their management of all laboratory aspects of the survey, confirming of all laboratc

serological reactions. Administration in Communicable Disease Surveillance Centre by Dr Mike Catchpole, Dr Noel Gill, Dr Chris Joyce, Ms Christine McGarrigle, Dr Angus Nicoll, Mrs Pauline Rogers, and Mr Ian Simms. The development of this survey, and others in the HIV prevalence monitoring programme in England and in the HIV prevalence monitoring programme in England and Wales, benefited from discussions with Dr David Goldberg a he Scottish Centre for Infection and Environmental Health and with Dr AV Swan of the PHLS Statistics Unit, Dr Danielle Mercey, Professor Mike Adler, and Professor Anne Johnson a he Department of STDs at University College London. This and other surveys in the programme were supported by the Department of Health for England. Initial guidance on design and direction was given by the UK Medical Research Council.

\section{Collaborative group}

The members of the survey group from 15 clinics and associated laboratories comprised: BS Azadian, FC Boag, P Carey, C Carne, D Carrington, E Claydon, P V Coyle, F Davidson, I Farrell, G Kinghorn, G Kudesia, R Maw, D Mercey, PR Mortimer, J Munro, S Murphy, K Mutton, M Nathan, L Neville, A Pozniak, JDC Ross, N Sankar, G Scott, MS Shafi, S Skidmore R Sparks, A Turner, A Wade, P Watkins, T Wreghitt, and M Zuckerman.

Contributors: Christine McGarrigle coordinated the Public Health Laboratory Service unlinked anonymous survey of GUM clinic attenders from mid-1996 onwards, assembled dat GUM clinic attenders from mid-1996 onwards, assembled data for the paper, and undertook the analyses and writing of the paper. Angus Nicoll contributed to analyses and writing of
paper, and managed the GUM survey from 1991 to 1997 .

1 Department of Health. HIV and AIDS health promotion: an evolving strategy. London: $\mathrm{DoH}, 1995$.

2 United Nations Programme on HIV/AIDS. Report on the global HIVIAIDS epidemic-June 1998. Geneva: World Health Organisation, 1998.

3 World Health Organisation (Europe). Stop emerging infectious diseases, World Health Day, 7 April 1997. Netherlands: WHO Regional Office for Europe, 1997.

4 Office of Populations, Censuses and Surveys and General Register Office for Scotland. 1991 Census, ethnic group and country of birth. Great Britain. London: HMSO, 1994

5 Office for National Statistics. Travel trends. A report on the 1995 international passenger survey. London: The Stationery 1995 internationc

6 Unlinked Anonymous Surveys Steering Group. Prevalence of HIV in England and Wales in 1996. Annual report of the Unlinked Anonymous Seroprevalence Monitoring Programme 
in England and Wales. London: Department of Health, Public Health Laboratory Service, Institute of Child Health (London), December 1997

7 Communicable Disease Surveillance Centre, Scottish Centre for Infection and Environmental Health, Institute of Child Health (London), and Oxford Haemophilia Centre. AIDS and HIV-1 Infection in the United Kingdom: monthly report. CDR 1997;7:355-6.

8 Paine K, Pozniak A, Chisholm D, et al. African communities in London: demography and the epidemiology and economics of HIV infection. London: Department of Genitourinary Medicine, Kings College, 1997.

9 Catchpole MC, Mercey DE, Nicoll A, et al. Continuing tranpoie MC, Mercey DE, Niconl A, et al. Conthuing transinission of STDs among patients infected with HIV-1 attending genitourinary medicine clinics in England and

10 Suligoi B, Guiliani M and the Migration Medicine Study Group. Sexually transmitted diseases among foreigners in Italy. Epidemiol Infect 1997;118:235-241.
11 Scott G, Goldberg D, Weir M, et al. Prevalence of HIV-1 infection among heterosexual men and women attending genitourinary clinics in Scotland: unlinked anonymous testing. BMF 1997;315:1281-2.

12 McGarrigle C, Gilbart V, Nicoll A. AIDS and HIV infection acquired heterosexually. CDR Rev 1997; 7:R125-8.

13 Bhopal R. Is research into ethnicity and health racist, unsound, or important science? BMF 1997;314:1751-6.

14 Low N, Dakar-White, Barlow D, et al. Gonorrhoea in inner London: results of a cross sectional study. BMF 1997;314: 1719-23.

15 De Cock KM, Low N. HIV/AIDS, sexually transmitted diseases, and tuberculosis in ethnic minorities in the United Kingdom: is surveillance serving its purpose? BMF 1997;314: $1747-51$.

16 Grosskurth H, Mosha F, Todd J, et al. Impact of improved treatment of sexually transmitted diseases on HIV infection in rural Tanzania: randomised controlled trial. Lancet 1995;346:530-6. 